Résumés des conférences et travaux

\title{
Les relations militaires franco-hongroises aux époques moderne et contemporaine
}

Ferenc Tóth

\section{(2) OpenEdition}

Journals

\section{Édition électronique}

URL : https://journals.openedition.org/ashp/4644

DOI : $10.4000 /$ ashp.4644

ISSN : 1969-6310

\section{Éditeur}

Publications de l'École Pratique des Hautes Études

\section{Édition imprimée}

Date de publication : 1 septembre 2021

Pagination : 352-356

ISSN : 0766-0677

\section{Référence électronique}

Ferenc Tóth, «Les relations militaires franco-hongroises aux époques moderne et contemporaine », Annuaire de l'École pratique des hautes études (EPHE), Section des sciences historiques et philologiques [En ligne], 152 | 2021, mis en ligne le 14 juin 2021, consulté le 13 juin 2022. URL : http:// journals.openedition.org/ashp/4644; DOI : https://doi.org/10.4000/ashp.4644 


\title{
LES RELATIONS MILITAIRES FRANCO-HONGROISES AUX ÉPOQUES MODERNE ET CONTEMPORAINE
}

\author{
Conférences de M. Ferenc Tóth, \\ Institut d'histoire du Centre de recherches en sciences humaines \\ (Académie hongroise des sciences, Budapest), \\ directeur d'études invité
}

Ce cycle de conférences visait à présenter une histoire générale des relations militaires franco-hongroises sur la base d'une introduction théorique sur la pensée militaire hongroise moderne suivie d'études de cas précis. L'histoire des pays d'Europe centrale, comme celle de la Hongrie, est peu connue en France; néanmoins certaines idées emblématiques persistent depuis des siècles et offrent des stéréotypes liés au caractère national guerrier et à l'esprit militaire de ces peuples. L'image des hussards hongrois, notamment, est toujours vivante dans l'opinion occidentale sans reposer sur une véritable connaissance historique des échanges militaires entre les deux cultures de guerres. Ces conférences voulaient présenter les nouveaux résultats des recherches récentes afin de mieux éclairer ces relations riches et fécondes.

Pour la bonne compréhension des choses, il convient de définir les espaces géographiques et les cadres temporels étudiés. On entend par l'espace français non seulement le territoire de la France historique, mais aussi, au sens large, un espace civilisationnel dominé par la France à l'époque moderne dans le domaine de la pensée stratégique. Ainsi, les penseurs francophones (wallons, lorrains, alsaciens, suisses, savoyards, etc.) sont considérés comme appartenant à la même aire culturelle que les sujets proprement dits des rois de France. De même, l'espace hongrois correspond à une entité beaucoup plus large que la Hongrie de nos jours, réduite à un tiers de ses territoires historiques et privés de ses sphères d'influence en Europe centrale et orientale suite aux changements du $\mathrm{Xx}^{\mathrm{e}}$ siècle.

La période concernée est une longue époque moderne et contemporaine allant du début $d u X V I^{e}$ siècle jusqu'au début du $\mathrm{XX}^{\mathrm{e}}$ siècle. Pour l'histoire hongroise, les deux extrémités en sont la bataille de Mohács (1526), fin de la puissance moyenne du royaume de Hongrie, et la chute de l'Empire austro-hongrois (1918). Cet intervalle couvre la période de l'occupation ottomane (1541-1699) et le règne de la dynastie des Habsbourg sur le trône de Hongrie (1526-1918). Dans l'historiographie hongroise, cela correspond à une époque de guerres turques et de luttes pour l'indépendance très riches en réflexions militaires. Pour l'histoire française, en revanche, la période examinée correspond davantage au renforcement de la grande puissance de la monarchie, en particulier sous le règne de Louis XIV. L'époque des Lumières nous apparaît souvent comme celle de la diffusion de la culture française en Europe. Néanmoins, à la même époque, la France bénéficiait également de l'influence des cultures de guerre d'Europe centrale et orientale dont l'importance n'est pas à démontrer. 
Dans le programme des conférences, on se proposait d'étudier les questions la diffusion des théories et tactiques entre les espaces historiques français et hongrois. La tactique inspirée des guerres turques en Hongrie est un cas de figure particulièrement intéressant, car c'est à cette époque que la manière de combattre à la hongroise, autrement dit la tactique de la petite guerre, commença à se répandre en Europe. La cavalerie légère hongroise - les hussards - apparut dans presque toutes les armées. Le succès incontestable des hussards en France montre bien que la petite guerre avait une place spécifique dans les guerres modernes. À l'heure où l'on redécouvre la guerre sainte du terrorisme global fondé sur l'islam fondamentaliste, il n'est pas indifférent de connaître les pensées des militaires qui réussirent à faire face à l'armée la plus puissante du monde oriental à l'époque étudiée. À l'heure où le Moyen-Orient est plus que jamais une poudrière, il peut être profitable de redécouvrir l'art militaire des Ottomans et de leurs opposants, les Hongrois et les Impériaux. Face aux conflits asymétriques qui semblent devenir fréquents, la réussite des armées révoltées hongroises contre l'armée impériale mérite également d'être méditée : elle rappelle que la victoire ne va pas nécessairement à celui qui possède la supériorité technique.

Dans une première conférence, on a dressé un tableau historique de la pensée militaire hongroise à l'époque moderne, très peu connue et souvent mal connue en France. Les deux conférences suivantes ont porté sur les théories militaires et stratégiques de deux penseurs, un chef d'armée impériale de culture française en Hongrie, le duc Charles $\mathrm{V}$ de Lorraine, et un officier et diplomate français d'origine hongroise, François de Tott. Ces deux hommes, aujourd'hui presque oubliés, ont joué un rôle d'intermédiaires entre les grandes cultures militaires occidentale et orientale. Enfin, la dernière conférence portait sur l'armée austro-hongroise au tournant des $\mathrm{XIX}^{\mathrm{e}}$ et $\mathrm{XX}^{\mathrm{e}}$ siècles.

\section{La pensée militaire hongroise à l'époque moderne}

La pensée militaire hongroise à l'époque moderne est un sujet assez mal connu en France et mérite à bien des égards quelques réflexions. La première partie de la conférence a été consacrée à une présentation géographique et historique de l'espace hongrois à l'époque de la première modernité. En présentant la problématique des frontières militaires du royaume de Hongrie, un aspect caractéristique a particulièrement retenu l'intérêt des auditeurs et une discussion s'est ouverte sur la stratégie fluviale des grands penseurs militaires des guerres turques en Hongrie (par ex. Montecuccoli, Charles de Lorraine, Marsigli, etc.). La guerre fluviale était d'autant plus importante que le Danube et ses affluents constituaient à la fois des frontières naturelles, des ressources d'eau et un excellent réseau de transport et communication. En présentant les principaux acteurs et penseurs, une importance a été accordée aux grands chefs militaires hongrois (comme N. Zrínyi, F. Rákóczi, A. Hadik), mais les idées stratégiques des grands généraux impériaux à la tête des armées coalisées (par ex. Montecuccoli, Eugène de Savoie) ont été également analysées dans la perspective d'une comparaison.

Hormis les grandes idées sur l'organisation des armées et la conduite de la guerre, on a souligné l'importance de la petite guerre à la hongroise au XVIII ${ }^{\mathrm{e}}$ siècle. Si les grands capitaines hongrois, comme le maréchal Berchény, au service de la France, se 
refusèrent à rédiger un traité sur la manière de combattre à la hongroise, l'ingénieur militaire Louis Michel Jeney nous laissa un ouvrage remarquable sur ce sujet (Le partisan ou l'art de faire la petite guerre, La Haye, 1759).

On a enfin présenté l'évolution du système de défense en Hongrie, surtout les changements survenus pendant les guerres turques sous la tutelle de la maison des Habsbourg. La question de la modernisation des armées apparaît souvent dans les ouvrages des penseurs militaires, même s'ils insistent parfois sur la survivance des anciennes institutions militaires et s'inspirent des influences ottomanes sur les armes et les tactiques militaires, surtout sur les confins de la Hongrie.

\section{La pensée militaire de Charles V de Lorraine et ses sources}

Après l'introduction générale, on a présenté l'exemple d'un chef militaire impérial de culture française, le duc Charles V de Lorraine, qui pouvait illustrer l'influence des idées modernes sur l'art de la guerre en Hongrie à l'époque de la reconquête du pays sur les Ottomans. Charles de Lorraine reste un des grands oubliés des histoires nationales. Comme il ne régna jamais sur ses duchés, il fut surnommé « duc sans duchés » et sa personne fut plus étroitement liée à l'histoire de l'Europe centrale, en particulier à celle de l'Autriche et plus encore de la Hongrie où il joua un rôle primordial. En septembre 1683, il contribua à la libération de la ville de Vienne avec le roi Jean III Sobieski. Ensuite, il mena plusieurs campagnes dans la Hongrie occupée par les Turcs. En 1686, il réussit à reprendre la ville de Bude et ouvrit ainsi la voie à une campagne victorieuse qui chassa les Turcs de la Slavonie et de la Transylvanie. Son Journal des campagnes manuscrit, composé par l'abbé François Le Bègue, décrit ses opérations militaires de 1683 jusqu'en 1689. Cet ouvrage, dont le manuscrit est conservé aux Archives nationales autrichiennes, a été récemment publié par nos soins. À partir de ce texte précieux ainsi que des papiers personnels du grand commandant, on a analysé les principaux éléments de sa pensée militaire.

$\mathrm{Au}$ terme de cette conférence, on a évoqué la découverte récente d'un journal autographe de la campagne de 1687 tenu par Charles V de Lorraine qui nous apparaît comme une source authentique sur les opérations militaires en Hongrie et en Transylvanie. Les comparaisons de ce texte avec le Journal rédigé par l'abbé Le Bègue nous permettent d'identifier les différentes fonctions du document autographe. Les informations fournies par ce texte sont d'autant plus précieuses qu'elles nous montrent le caractère caché de la guerre, qui n'existe pas dans les œuvres d'historiens plutôt destinées à faire l'éloge des princes. Sous la plume du duc, la guerre apparaît dans sa nature cruelle et incertaine qui déconcerte même le chef le plus talentueux. Les hésitations, les imprévus voire les erreurs y sont décrits d'une manière tout à fait remarquable. Cela n'enlève rien aux qualités militaires du duc Charles V de Lorraine, mais fait toucher du doigt les difficultés extrêmes de la guerre turque en Hongrie.

III. Un penseur stratégique du XVIII e siècle : François baron de Tott (1733-1793)

La troisième conférence montrait l'exemple d'une carrière contraire, c'est-à-dire d'un officier d'origine hongroise au service de la France à l'époque des Lumières. 
Après l'échec de la guerre d'indépendance hongroise, de nombreux émigrés hongrois arrivèrent en France où ils furent employés dans les régiments de hussards. Quelques membres de l'élite hongroise en France remplirent des missions diplomatiques en Orient. François de Tott fut incontestablement le plus connu. Son père, un officier de hussards et diplomate, l'avait préparé à ces fonctions en l'emmenant en Turquie pour y apprendre la langue. Ensuite, il fit plusieurs séjours en Orient. En 1767-1769, il fut envoyé en Crimée tant que consul. En 1770-1775, il participa à la défense de Constantinople durant la guerre russo-turque de 1768-1774 puis contribua aux réformes de l'armée ottomane. Sa dernière grande mission, en 1777-1778, fut l'inspection des Échelles du Levant et de la Barbarie, doublée d'une mission secrète préparant une éventuelle conquête de l'Égypte. À la fin de sa vie, il publia les Mémoires du baron de Tott sur les Turcs et les Tartares ( $1^{\mathrm{re}}$ éd. Amsterdam, 1784). Cet ouvrage remporta un succès considérable : cinq éditions en deux ans, traductions en allemand, anglais, danois et hollandais. Très rapidement, il devint un ouvrage de référence pour les penseurs politiques et militaires de l'époque.

Après avoir édité les Mémoires et une biographie de l'auteur, on voulait montrer la modernité de sa pensée stratégique, qui eut une influence importante sur la génération suivante. Les idées militaires les plus originales du baron de Tott apparaissent dans ses rapports diplomatiques. En tant qu'ancien consul de France en Crimée, il sut profiter de son séjour pour décrire l'art de la petite guerre des Tatars. Lors de son séjour en Turquie, il rédigea plusieurs mémoires sur le système militaire ottoman en vue de proposer des réformes. Après sa mission secrète en Égypte, il prépara un plan d'occupation de ce pays qui fut consulté par Napoléon Bonaparte avant sa célèbre campagne de 1798. Ses réflexions géostratégiques, notamment sur l'importance de la fortification des détroits des Dardanelles et du Bosphore ou sur le rétablissement du canal de Suez, le rapprochent des penseurs du siècle suivant.

\section{L'armée austro-hongroise entre mythe et réalité}

Pour terminer ce cycle de conférences, on a choisi de présenter l'armée austro-hongroise, qui bénéficiait à la fois des traditions hongroises et de la modernisation occidentale du XIX ${ }^{\mathrm{e}}$ siècle. Cette force armée multinationale mérite à bien des égards notre attention. Pour certains historiens, elle constituait la préfiguration d'une véritable armée européenne dont la brûlante actualité n'est pas à démontrer. Comme produit d'une longue évolution et d'une série de compromis, cette armée était beaucoup plus qu'une institution militaire : ses réformes avaient également un impact sur la société. En analysant le corps des officiers de l'armée impériale-royale du XIX ${ }^{\mathrm{e}}$ siècle, il convient de souligner le rôle clé de cette couche sociale protégeant l'ordre intérieur et assurant la cohésion de la monarchie. Originaire de la noblesse militaire, le corps d'officiers commença à s'ouvrir aux classes inférieures, offrant une perspective d'ascension sociale extraordinaire à beaucoup de jeunes d'origine modeste.

Grâce aux changements structurels du début du règne de François-Joseph I ${ }^{\text {er }}$, la modernisation militaire avait déjà produit des résultats dans les années 1850 . Toutefois, ces réformes n'étaient pas suffisantes pour renforcer le poids militaire de la Monarchie en Europe. Les défaites militaires au tournant des années 1850-1860 (p. ex. Solferino 
en 1859 et Königgrätz-Sadowa en 1866) provoquèrent des changements plus considérables qui aboutirent aux réformes militaires dans le cadre du Compromis de 1867. On a analysé les différentes parties du nouveau système de défense, l'armée commune d'une part, les forces nationales de l'autre, Landwehr autrichien et Honvédség hongrois. On a accordé une importance particulière aux questions pratiques, comme la direction et le fonctionnement de ces forces armées extrêmement hétérogènes. La question linguistique, les problèmes religieux et culturels ainsi que la montée des mouvements nationaux constituaient des difficultés très difficiles à surmonter, mais cette armée exista jusqu'à la fin de la Grande Guerre. Les faiblesses dues au manque de modernisation, l'échec de la stratégie de la guerre-éclair et les revers subis durant la première période de la guerre contribuèrent largement à sa défaite et à sa disparition.

Dans notre cycle de conférences, on a insisté sur l'importance de l'époque moderne qui constitua une époque charnière des grands changements. De nombreux historiens ont montré la modernité des guerres des $\mathrm{XVII}^{\mathrm{e}}-\mathrm{XIX}^{\mathrm{e}}$ siècles, qu'ils qualifient de premières manifestations de la guerre totale. C'est aussi à cette époque que se mit en place la tactique de la petite guerre, qui préfigure les stratégies asymétriques de notre époque. Le comte de Montecuccoli fut l'un des fondateurs de la pensée militaire européenne et certaines des préoccupations exprimées dans ses Mémoires ne sont pas dépourvues d'actualité. Un autre auteur quasiment inconnu, le baron de Tott, a fait découvrir à l'Europe occidentale des formes de guerre orientales qui seront perfectionnées au siècle suivant par les spécialistes des guerres coloniales. Il n'est pas inutile de redécouvrir les fondations d'un édifice qui continue à structurer les institutions militaires de notre temps. Ces exemples lointains peuvent éclairer notre analyse de la complexité stratégique contemporaine. 